\title{
Pemilihan Hotel Pada Kelurahan Oesapa Selatan Menggunakan Metode Weighted Product
}

\author{
Yampi R Kaesmetan ${ }^{1}$, Yesaya Laga Nawa ${ }^{2}$ \\ ${ }^{1}$ Stikom Uyelindo Kupang,Jl. Perintis Kemerdekaan 1 Kayu Putih, Kupang-NTT \\ Email: kaesmetanyampi@gmail.com yesayalaganawa11@yahoo.com
}

\begin{abstract}
Hotel is one of the supporting facilities of tourism in a city. The diversity of the hotel make tourists often faced difficulty in determining the choice of hotel that suits your needs and desired criteria. Through a computerized application, can help prioritize the selection of the hotel. The results of the election study with WP method can be used to perform perangkingan list of alternatives hotel in southern Oesapa village for visitors so that the hotel needs can be met based on the criteria of visitors. The output of this system in the form of priority Oesapa best hotel in the southern villages. With this application, people who want to stay at the hotel can be easier in choosing a hotel to suit the need.
\end{abstract}

Keywords: Hotel, South Oesapa, Wighted Product.

\section{Pendahuluan}

\section{Latar Belakang}

Pemilihan hotel sesuai dengan harga, fasilitas dan sarana yang diinginkan dan sesuai dengan kebutuhan merupakan hal yang tidak mudah bagi pengunjung. Hal tersebut dikarenakan banyaknya pilihan hotel yang tersedia di seluruh Indonesia yang bersaing dalam pelayanan kepada pengunjung.

Masalah terjadi ketika pengunjung melakukan pemilihan hotel terbaik sesuai kebutuhan dan keinginan pengunjung dari berbagai hotel yang ada di kelurahan Oesapa Selatan. Masalah tersebut merupakan masalah yang semi terstruktur dalam memutuskan hotel yang akan dipilih sebagai alternatif terbaik bagi pengunjung.

Karena pertimbangan dari pengunjung menjadi bagian dari prosedur yang harus dipenuhi dalam pengambilan suatu keputusaan pemilihan hotel. Masalah semi terstrukur dapat dipecahkan menggunakan sistem penunjang keputusan dengan cara memberi informasi atau usulan menuju pada keputusan tertentu. Sehingga pengambil keputusan, akan mendapatkan rekomendasi keputusan sesuai dengan kriteria yang dinginkan. Pemilihan Hotel terbaik sesuai kebutuhan dan keinginan pengunjung dapat dibantu dengan bantuan metode WP.

Metode Weighted Product merupakan salah satu metode penyelesaian yang ditawarkan untuk menyelesaikan masalah Multi Attribute Decision Making (MADM) yang dapat digunakan dalam pengambilan keputusan untuk mencari suatu alternatif terbaik dari berbagai alternatif berdasarkan kriteria - kriteria yang telah ditentukan. Intinya bahwa metode tersebut menentukan nilai bobot pada setiap kriteria (Gerdon, 2011).

Pemilihan hotel pada kelurahan oesapa menggunakan metode WP ini membantu memberikan solusi bagi pengunjung dalam pengambilan keputusan pemilihan hotel di kelurahan Oesapa Selatan dengan tepat sesuai kebutuhannya.

\section{Perumusan Masalah}

Masalah di dalam penelitian ini yaitu bagaimana menerapkan metode Weighted Product untuk mendapatkan nilai rangking yang tertinggi pemilihan hotel pada kelurahan oesapa selatan. 


\section{Tujuan dan Manfaat}

Tujuan penulisan paper ini adalah mendapatkan nilai alternatif tertinggi dari pemilihan hotel agar pengunjung dapat memilih hotel yang sesuai dengan kebutuhan. Sehubungan dengan telah dirumuskannya permasalahan, maka diharapkan ini dapat memberikan manfaat antara lain:

a. Bagi masyarakat luas khususnya warga Kelurahan Oesapa Selatan dan pengunjung yang ingin mengunjungi hotel di Kelurahan Nunbaun Sabu agar bisa memilih hotel yang sesuai dengan kebutuhan.

b. Hasil penelitian ini dapat digunakan sebagai referensi untuk akademis atau peneliti selanjutnya yang ingin membahas mengenai metode Weighted Product (WP).

\section{Ruang Lingkup}

Agar pembahasan masalah terarah dan tidak menyimpang dari tujuan penelitian maka berikut adalah batasan yang dibuat sebagai ruang lingkup penelitian, yakni sebagai berikut:

a. Fokus objek penelitian ini dilakukan hanya di Kelurahan Oesapa Selatan sebagai sampel penelitan.

b. Penelitian ini hanya meneliti pemilihan hotel menggunakan metode WP.

c. Alternatif data yang dipakai dalam penelitian ini adalah Hotel T-More, Hotel Le-Deletadu, dan Hotel Yotowawa (By Brenton Hotel) dengan krikteria harga, fasilitas, kelas, pelayanan, dan jarak.

\section{Tinjauan Penelitian Terdahulu}

Beberapa penelitian terdahulu yang berkaitan dengan penelitian pemilihan hotel pada kelurahan oesapa selatan menggunakan metode WP yaitu sebagai berikut:

Penelitian yang dilakukan oleh Heru Supriyono dan Chintya Purnama Sari dengan judul Pemilihan Rumah Tinggal Menggunakan Metode Weighted Product penelitian ini berhasil membuat sistem yang dapat memilih rumah tinggal yang sesuai dengan kebutuhan masyarakat. Dengan metode yang digunakan maka akan didapatkan nilai hasil perengkingan nilai dari kriteria pemilihan rumah tinggal terbaik.

Penelitian yang dilakukan oleh Muslim Hidayat dan M. Alif Muafiq Baihaqi dengan judul Sistem Pendukung Keputusan Pemilihan Hotel Dengan Metode SAW penelitian ini adalah SPK dengan Metode SAW ini dapat digunakan untuk melakukan perangkingan daftar alternatife hotel di tiket.com bagi pengunjung sehingga kebutuhan hotel dapat terpenuhi berdasarkan kriteria pengunjung.

Penelitian yang dilakukan oleh Aziz Ahmadi dan Dian Tri Wiyanti dengan judul Implementasi Weighted Product (WP) dalam Penentuan Penerima Bantuan Langsung Masyarakat PNPM Mandiri Perdesaan penelitian ini berhasil membuat sistem yang dapat menentukan desa dengan prioritas tertinggi untuk mendapatkan BLM dari sekian alternatif desa pengusul dengan menggunakan metode Weighted Product (WP).

Penelitian yang dilakukan oleh Danik Kusumawardani dengan judul Sistem Pendukung Keputusan Penerima Bantuan Rumah Layak Huni Dengan Menggunakan Metode Weighted Product (WP) penelitian ini berhasil membuat sistem pendukung keputusan penerimaan bantuan rumah layak huni di Desa Pacinan dan akan membantu pihak desa dalam menentukan penduduk yang benar-benar membutuhkan bantuan rumah layak huni melalui data perangkingan dari hasil yang telah diolah dalam sistem tersebut. Aplikasi sistem pendukung keputusan ini membuktikan metode Weighted Product dapat di implementasikan kedalam sisitem dan telah dibuktikan pada saat pengujian penelitian.

\section{Landasan Teori}

\section{a. Metode WP (Weighted Product)}

Metode Weighted Product (WP) adalah himpunan berhingga dari alternatif keputusan yang dijelaskan dalam beberapa hal kriteria keputusan.

Metode Weighted Product (WP) merupakan salah satu dari beberapa metode MADM (Multi Atribute Decision Making). Metode MADM merupakan metode pengambilan keputusan yang didasarkan pada beberapa atribut. Konsep permasalahannya adalah mengevaluasi $\mathrm{m}$ alternatif $\mathrm{Ai}(\mathrm{i}=1,2, \ldots, \mathrm{m})$ terhadap sekumpulan atribut atau kriteria $\mathrm{Cj}(\mathrm{j}=1,2, \ldots, \mathrm{n})$, dimana setiap atribut tidak saling bergantung satu dengan yang 
lainnya. Metode ini mengharuskan pembuat keputusan menentukan bobot bagi setiap atribut. Langkah-langkah penyelesaian menggunakan metode WP yaitu sebagai berikut:

1. Menentukan tingkat prioritas bobot setiap kriteria (W_Initj) kemudian dilakukan perbaikan bobot $(\mathrm{Wj})$ menggunakan rumus berikut.

$$
W j=\frac{W_{-} \text {Init }_{j}}{\sum W_{-} \text {Init }_{j}} \text {. }
$$

Keterangan : $\mathrm{n}$ menyatakan banyak kriteria

2. Membuat tabel bobot kriteria yang akan dipilih Tabel 1. Tabel bobot kriteria

\begin{tabular}{|l|l|l|l|l|}
\hline $\begin{array}{l}\text { Alternatif } \\
\left(\mathrm{A}_{\mathrm{i}}\right)\end{array}$ & \multicolumn{4}{l|}{ Kriteria } \\
\cline { 2 - 5 } & $\mathrm{C}_{1}$ & $\mathrm{C}_{2}$ & $\ldots$ & $\mathrm{C}_{\mathrm{n}}$ \\
\hline Item 1 & $\mathrm{X}_{11}$ & $\ldots$ & $\ldots$ & $\mathrm{X}_{1 \mathrm{n}}$ \\
\hline Item 2 & $\ldots$ & $\ldots$ & $\ldots$ & $\ldots$ \\
\hline$\ldots$ & $\ldots$ & $\ldots$ & $\ldots$ & $\ldots$ \\
\hline Item $m$ & $\mathrm{X}_{\mathrm{m} 1}$ & $\ldots$ & $\ldots$ & $\mathrm{X}_{\mathrm{mn}}$ \\
\hline
\end{tabular}

$m$ mewakili banyak Item.

3. Menghitung vektor $\mathrm{Si}$, dimana setiap data (Xij) akan dikalikan tetapi sebelumnya dilakukan pemangkatan dengan bobot dari kriterianya.

$$
S_{i}=\prod_{j=1}^{n} X_{i j}{ }^{k W_{j}}
$$

Dengan $\mathrm{i}=1,2, \ldots, \mathrm{m}$ dimana $\sum_{j=1}^{n} W j=1, \mathrm{k}=1$ untuk atribut keuntungan, $\mathrm{k}=-1$ untuk atribut biaya.

Keterangan :

S menyatakan preferensi alternatif,

$\mathrm{x}$ menyatakan nilai kriteria,

w menyatakan bobot kriteria,

n menyatakan banyaknya kriteria.

$\mathrm{Wj}$ adalah pangkat bernilai positif untuk atribut keuntungan, dan bernilai negatif untuk atribut biaya.

4. Menghitung vektor Vi kemudian memilih nilai tertinggi sebagai alternatif terbaik dalam pengambilan keputusan.

$$
V i=\frac{s_{i}}{\sum_{j=1}^{m} s_{i}}, \text { dengan } \mathrm{i}=1,2, \ldots, \mathrm{m} .
$$

\section{b. Oesapa Selatan}

Kelurahan Oesapa Selatan adalah Kelurahan yang dimekarkan dari Kelurahan Oesapa yang terletak di bagian selatan dan diresmikan oleh Bapak Walikota Kupang pada tanggal 25 April 2006 berdasarkan Perda Kota Kupang, Nomor 7
Tahun 2006 tentang Pemekaran Kelurahan Oesapa Selatan Kecamatan Kelapa Lima Kota Kupang.

Kelurahan Oesapa Selatan mempunyai batas wilayah sebagai berikut :

Utara : berbatasan dengan Kelurahan Oesapa

Selatan : berbatasan dengan Kelurahan Liliba

Timur : berbatasan dengan Kelurahan Lasiana dan Penfui

Barat : berbatasan dengan Kelurahan Liliba

Kelurahan Oesapa Selatan mempunyai Luas

Wilayah 1,2 $\mathrm{km}^{2}$ dengan jumlah penduduk sebanyak 4101 jiwa, dengan perincian :

$\begin{array}{lll}\text { Laki-Laki } & : 2336 & \text { Jiwa } \\ \text { Perempuan } & : 1765 \text { Jiwa } \\ \text { Jumlah KK } & : 614 \quad \text { KK }\end{array}$

\section{c. Hotel}

Hotel adalah suatu bentuk bangunan, lambang, perusahaan atau badan usaha akomodasi yang menyediakan pelayanan jasa penginapan, penyedia makanan dan minuman serta fasilitas jasa lainnya dimana semua pelayanan itu diperuntukkan bagi masyarakat umum, baik mereka yang bermalam di hotel tersebut ataupun mereka yang hanya menggunakan fasilitas tertentu yang dimiliki hotel itu. Hotel yang ada pada kelurahan oesapa selatan antara lain T-More Hotel, Hotel Le-Deletadu, dan Hotel Yotowawa (By Brenton Hotel).

\section{Metode Penelitian}

\section{Teknik pengumpulan Data}

Metode yang digunakan dalam proses pengumpulan data adalah:

a. Wawancara Metode ini dilakukan dengan cara tanya jawab secara langsung kepada bagianbagian yang terkait dengan pihak lain yang berkompeten untuk menanyakan beberapa pertanyaan yang terkait dengan kendala yang dihadapi dan permasalahan pada proses pembagian beras miskin.

b. Observasi Pengumpulan dengan cara melakukan penelitian secara langsung di Kelurahan Pongangan, dan melakukan pencatatan terhadap gejala - gejala yang ada yang berhubungan dengan masalah yang diteliti.

c. Studi Kepustakaan Pengumpulan data dengan cara mempelajari buku literature, laporan laporan dan hasil penelitian yang telah dilakukan terdahulu yang berhubungan dengan masalah penelitian. 


\section{Prosedur Penelitian Data}

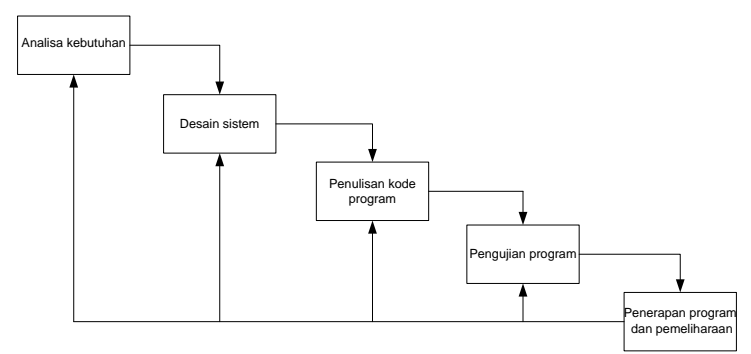

Gambar 1. Metode Waterfall

\section{Tahapan Metode Waterfall}

\section{Analisa Kebutuhan}

Dalam langkah ini merupakan analisa terhadap kebutuhan sistem. Langkah ini merupakan analisa terhadap kebutuhan sistem. Pengumpulan data dalam tahap ini dengan melakukan studi kepustakaan tentang pemilihan hotel menggunakan metode Weighted Product.

\section{Desain Sistem}

Tahapan dimana dilakukan penuangan pikiran dan perancangan sistem yang berdasarkan hasil analisa kebutuhan terhadap solusi dari permasalahan yang ada dengan menggunakan perangkat pemodelan sistem seperti use case diagram dan bahasan data.

\section{Penulisan Kode Program}

Penulisan kode program atau coding merupakan penerjemahan design dalam bahasa yang bisa dikenali oleh komputer yang dilakukan oleh programmer yang akan menterjemahkan transaksi yang akan diminta oleh pengguna. Tahapan inilah yang akan merupakan tahapan secara nyata dalam mengerjakan suatu sistem. Dalam artian penggunaan komputer akan dimaksimalkan dalam tahapan ini. Setelah pengkodean selesai maka akan dilakukan testing terhadap sistem yang telah dibuat sebelumnya.

\section{Pengujian Program}

Tahapan akhir dimana sistem yang baru diuji kemampuan dan keefektifannya sehingga akan ditemukan kekurangan dan kelemahan sistem yang kemudian akan dilakukan pengkajian ulang dan perbaikan terhadap aplikasi menjadi lebih baik dan sempurna. Pengujian dilakukan dengan black box testing yaitu dengan hanya mengamati hasil eksekusi melalui data uji dan memeriksa fungsional dari perangkat lunak. Mengevaluasi hanya dari tampilan luarnya (interface) dan fungsionalitasnya, tanpa mengetahui apa yang terjadi dalam proses detailnya (hanya mengetahui input dan output).

\section{Penerapan Program dan Pemeliharaan}

Perangkat lunak yang telah disampaikan kepada seseorang pasti akan mengalami perubahan. Perubahan tersebut bisa dikarenakan mengalami kesalahan karena perangkat lunak harus menyesuaikan dengan lingkungan (periperal atau sistem operasi baru) atau karena seseorang membutuhkan perkembangan fungsional.

\section{Proses Pengambilan Keputusan}

Dalam penyeleksian penentuan hotel yang sesuai dengan kriteria yang diinginkan, akan menggunakan metode Fuzzy Multiple Attribute Decision Making (FMADM) dengan metode Weighted Product (WP).

Metode tersebut memerlukan kriteria-kriteria dan bobot untuk melakukan perhitungannya sehingga akan didapat alternatif terbaik. Metode WP mengenal adanya 2 (dua) atribut yaitu kriteria keuntungan (benefit) dan kriteria biaya (cost). Perbedaan mendasar dari kedua kriteria ini adalah dalam pemilihan kriteria ketika mengambil keputusan.

Dalam metode penelitian ini ada bobot dan kriteria yang dibutuhkan untuk menentukan hotel yang akan terseleksi sebagai hotel terpilih. Kriteria yang digunakan adalah:

1. C1 : Harga sewa kamar hotel (cost)

2. C2: Fasilitas hotel (benefit)

3. C3 : Kelas Hotel (benefit)

4. C4 : Peleyanan Hotel (benefit)

5. C5 : Jarak Hotel (benefit)

Berdasarkah hasil survey terdapat 3 hotel yang ada pada kelurahan oesapa selatan antara lain:

1. A1 : Hotel T-More

2. A2 : Hotel Le-Deletadu

3. A3 : Hotel Yotowawa

\section{Hasil Dan Pembahasan}

Dalam melakukan evaluasi terhadap pengunjung dalam pemilihan hotel pada kelurahan oesapa selatan menggunakan 
metode weighted product. Berikut langkahlangkah perhitungan manual penyelesaian penelitian dengan menggunakan metode weighted product adalah sebagai berikut:

a. Menentukan tingkat prioritas bobot

Proses selanjutnya adalah pembobotan preferensi (W) dari masing-masing kriteria. Pemberian bobot dilakukan oleh pengunjung berdasarkan kepentinganya. Sebagai contoh pengambil keputusan memberikan bobot sebagai berikut:

Harga $=35$, Fasilitas $=20$, Kelas $=15$, Pelayanan $=10$, Jarak $=20$

$$
\mathrm{W}=\left[\begin{array}{lllll}
35 & 20 & 15 & 10 & 20
\end{array}\right]
$$

b. Menentukan tabel nilai alternatif setiap kriteria

1) Kriteria harga sewa kamar hotel

Kriteria harga sewa kamar hotel dapat dilihat pada tabel berikut:

Tabel 2. Harga sewa kamar hotel (C1)

\begin{tabular}{|l|c|}
\hline $\begin{array}{l}\text { Berdasarkan Harga Sewa } \\
\text { Kamar Hotel (Min.) }(\mathrm{C} 1)\end{array}$ & Nilai \\
\hline $\mathrm{C} 1<150.000$ & 1 \\
\hline $151.000<=\mathrm{C} 1<200.000$ & 2 \\
\hline $201.000<=\mathrm{C} 1<500.000$ & 3 \\
\hline $501.000<=\mathrm{C} 1<1.000 .000$ & 4 \\
\hline $\mathrm{C} 1>=1.001 .000$ & 5 \\
\hline
\end{tabular}

2) Kriteria fasilitas hotel

Kriteria fasilitas hotel dapat dilihat pada tabel berikut:

Tabel 3. Fasilitas hotel (C2)

\begin{tabular}{|l|c|}
\hline \multicolumn{1}{|c|}{ Fasilitas Hotel (C2) } & Nilai \\
\hline Tidak Lengkap & 1 \\
\hline Kurang Lengkap & 2 \\
\hline Cukup Lengkap & 3 \\
\hline Lengkap & 4 \\
\hline Sangat Lengkap & 5 \\
\hline
\end{tabular}

3) Kriteria kelas hotel

Kriteria kelas hotel dapat dilihat pada tabel berikut:

Tabel 4. Tingkat kelas hotel (C3)

\begin{tabular}{|l|c|}
\hline \multicolumn{1}{|c|}{ Kelas Hotel (C3) } & Nilai \\
\hline Bintang 1 & 1 \\
\hline Bintang 2 & 2 \\
\hline Bintang 3 & 3 \\
\hline Bintang 4 & 4 \\
\hline Bintang 5 & 5 \\
\hline
\end{tabular}

4) Kriteria pelayanan hotel

Kriteria pelayanan hotel dapat dilihat pada tabel berikut:

Tabel 5. Tingkat pelayanan hotel (C4)

\begin{tabular}{|l|c|}
\hline \multicolumn{1}{|c|}{ Kelas Hotel (C4) } & Nilai \\
\hline Tidak Sesuai & 1 \\
\hline Kurang Sesuai & 2 \\
\hline Cukup Sesuai & 3 \\
\hline Sesuai & 4 \\
\hline Sangat Sesuai & 5 \\
\hline
\end{tabular}

5) Kriteria jarak hotel berikut:

Kriteria jarak hotel dapat dilihat pada tabel

Tabel 6. Tingkat jarak hotel (C5)

\begin{tabular}{|l|c|}
\hline \multicolumn{1}{|c|}{ Jarak Hotel (C5) } & Nilai \\
\hline Dari Bandara & 3,1 \\
\hline Dari Bandara & 2,7 \\
\hline Dari Bandara & 2,3 \\
\hline
\end{tabular}

Dari nilai setiap kriteria pada tabel 2-6 diatas, maka didapatkan nilai alternatif keputusan sebagai berikut:

Tabel 7. Tabel nilai alternatif setiap kriteria

\begin{tabular}{|c|c|c|c|c|c|}
\hline \multirow{2}{*}{ Alternatif } & \multicolumn{5}{|c|}{ Kriteria } \\
\cline { 2 - 6 } & C1 & C2 & C3 & C4 & C5 \\
\hline A1 & 3 & 4 & 3 & 5 & 3,1 \\
\hline A2 & 2 & 3 & 2 & 3 & 2,7 \\
\hline A3 & 1 & 2 & 1 & 2 & 2,3 \\
\hline
\end{tabular}

Tabel 8. Tabel W Initj (Bobot)

\begin{tabular}{|c|c|c|c|c|}
\hline W1 & W2 & W3 & W4 & W5 \\
\hline 35 & 20 & 15 & 10 & 20 \\
\hline
\end{tabular}

Tabel 9. Tabel Inisialisasi Nilai Winitj

\begin{tabular}{|c|c|c|c|c|}
\hline W1 & W2 & W3 & W4 & W5 \\
\hline$-0,3500$ & 0,2000 & 0,1500 & 0,1000 & 0,2000 \\
\hline COST & $\begin{array}{c}\text { BENEFI } \\
\mathrm{T}\end{array}$ & $\begin{array}{c}\text { BENEFI } \\
\mathrm{T}\end{array}$ & $\begin{array}{c}\text { BENEFI } \\
\mathrm{T}\end{array}$ & $\begin{array}{c}\text { BENEFI } \\
\mathrm{T}\end{array}$ \\
\hline $\begin{aligned} \mathrm{W} 1 & =3 \\
\mathrm{~W} 2 & =2 \\
\mathrm{~W} 3 & =1 \\
\mathrm{~W} 4 & =1 \\
\mathrm{~W} 5 & =2\end{aligned}$ & $\begin{array}{l}/(35+20- \\
/ /(35+20- \\
/ /(35+20- \\
/(35+20- \\
/ /(35+20\end{array}$ & $\begin{array}{l}15+10+20 \\
15+10+20 \\
15+10+20 \\
15+10+20 \\
15+10+20\end{array}$ & $\begin{aligned}-1 & =-0,3 \\
& =0,20 \\
& =0,15 \\
& =0,10 \\
& =0,20\end{aligned}$ & \\
\hline $\begin{array}{l}\text { c. Me } \\
\text { S1 }= \\
\left(5^{\wedge} 0,10\right. \\
\mathrm{S} 2= \\
\left(3^{\wedge} 0,10\right. \\
\mathrm{S} 3= \\
\left(2^{\wedge} 0,10\right. \\
\text { Jumlah }\end{array}$ & $\begin{array}{l}\text { ghitung } n \\
\wedge-0,3500) \\
0) *\left(3,1^{\wedge}\right. \\
\wedge-0,3500) \\
0) *(2,7 \wedge \\
\wedge-0,3500) \\
0) *\left(2,3^{\wedge}\right. \\
\text { lektor }\end{array}$ & $\begin{array}{l}\text { ai dari Ve } \\
*\left(4^{\wedge} 0,20\right. \\
, 2000)=1 \\
*\left(3^{\wedge} 0,20\right. \\
, 2000)=1 \\
*\left(2^{\wedge} 0,20\right. \\
, 2000)=1 \\
1,56012+ \\
4,49082\end{array}$ & $\begin{array}{l}\text { or }(\mathrm{Si}) \\
0) *\left(3^{\wedge}\right. \\
56012 \\
0) *\left(2^{\wedge}\right. \\
47640 \\
0) *\left(1^{\wedge} \times\right. \\
45430 \\
47640+1,\end{array}$ & $\begin{array}{l}1500) * \\
1500) * \\
1500) * \\
530\end{array}$ \\
\hline
\end{tabular}


d. Menghitung Vektor (Vi)

$\mathrm{V} 1=1,56012 / 4,49082=0,34740$

$\mathrm{V} 2=1,47640 / 4,49082=0,32876$

$\mathrm{V} 3=1,45430 / 4,49082=0,32384$

Dari hasil akhir perangkingan nilai tertinggi terdapat pada $\mathrm{V} 1$, sehingga A1 merupakan alternatif yang dipilih. Dengan kata lain Hotel TMore dipilih sebagai hotel yang sesuai dengan kebutuhan pengunjung hotel.

Hasil implementasi dengan menggunakan aplikasi matlab berbasis GUI sebagai berikut :

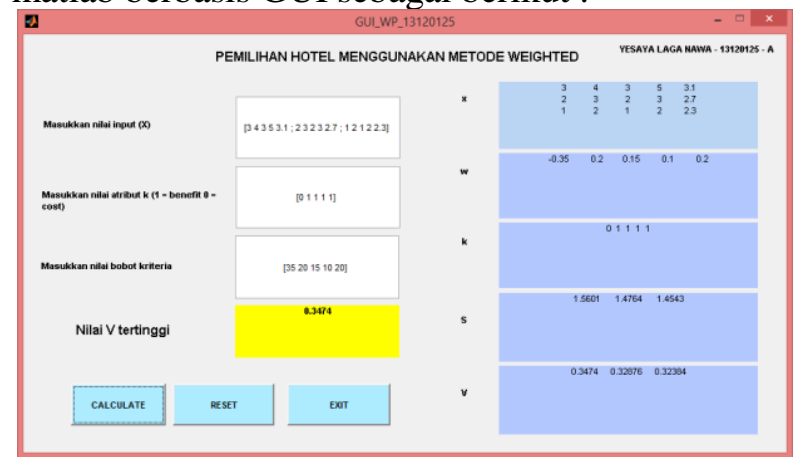

Gambar 2. Tampilan gui metode WP

Pada gambar 2 terlihat nilai $\mathrm{V}$ tertinggi di peroleh 0.347 , dengan inputan nilai $\mathrm{X}$ dan nilai $\mathrm{K}$. Pada Gambar 3 merupakan data peta kelurahan Oesapa Selatan yang sudah dikerjakan menggunakan Arcview dan Josm.

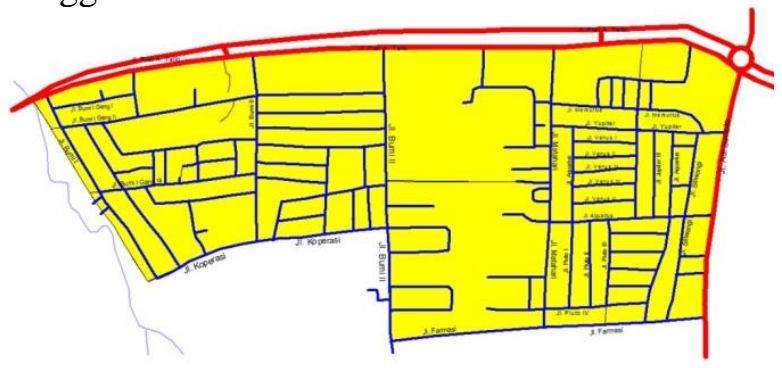

Gambar 3. Peta Oesapa Selatan dengan arcview

Peta kelurahan Oesapa Selatan yang digambar menggunakan josm, pada gambar 4 peta kelurahan sebelum dilakukan digitasi pada area lokasi Oesapa Selatan menggunakan josm sebagai berikut:

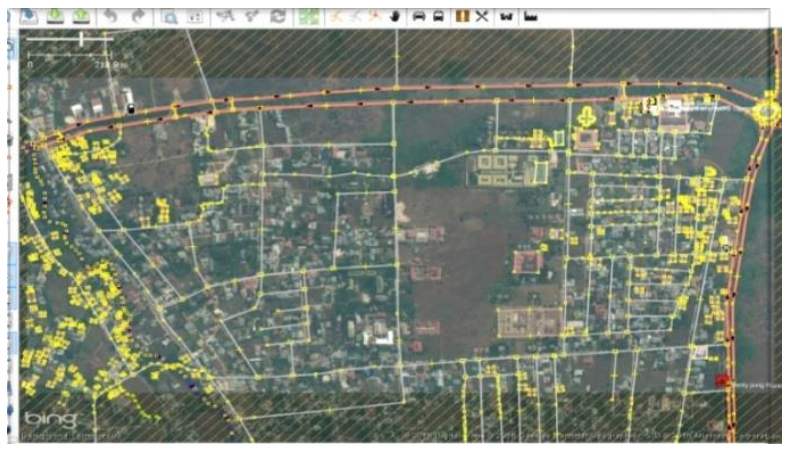

Gambar 4. Peta oesapa selatan sebelum digambar menggunakan josm

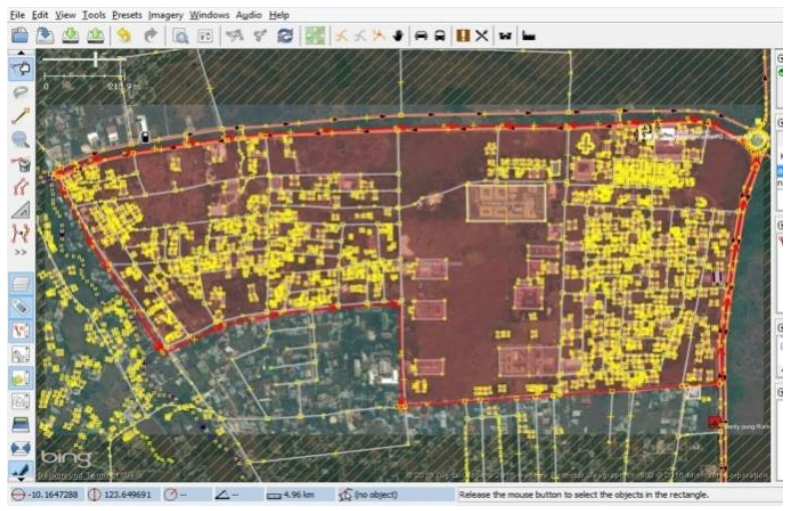

Gambar 5. Peta oesapa selatan sesudah digambar menggunakan josm

Pada gambar 5 digitasi sudah dilakukan pada lokasi Oesapa Selatan dan terdata sejumlah hotel yang dijadikan sebagai sampel penelitian, sedangkan pada gambar 6 terlihat implementasi dengan menggunakan metode Weighted Product (WP) .

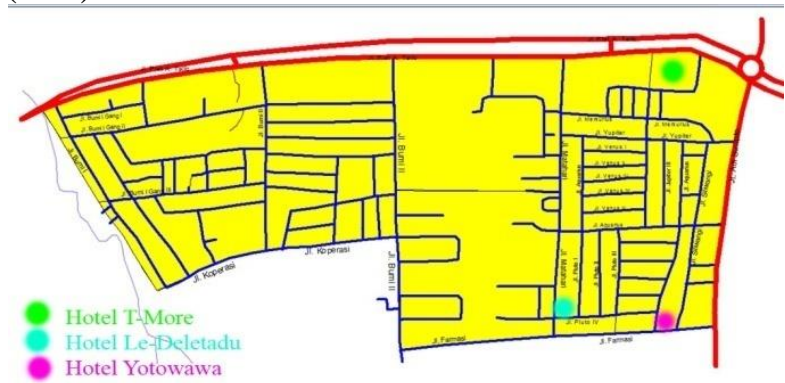

Gambar 6. Peta yang sudah diimplementasikan dengan metode WP

\section{Penutup}

\section{Kesimpulan}

Berdasarkan penelitian yang telah dilakukan dari tahap analisis, perancangan sistem, pengkodean, dan pengujian sistem, maka dapat ditarik beberapa kesimpulan yaitu:

Pemilihan Hotel di Kelurahan Oesapa Selatan telah berhasil dibangun. 
Metode Weighted Product (WP) untuk memperoleh alternatif rekomendasi hotel sebagai alat bantu pengambilan keputusan pemilihan hotel berhasil diterapkan dan dapat membantu memberikan acuan bagi pengunjung dalam memilih hotel yang ada di kelurahan oesapa selatan.

\section{Saran}

Penelitian ini dapat dikembangkan dengan menggunakan kombinasi metode lain, agar mendapat perbedaan hasil yang dicapai. Penelitian ini juga dapat dikembangkan dengan membuat sebuah aplikasi pemilihan hotel dengan bahasa pemrograman lain.

\section{DAFTAR PUSTAKA}

[1] Hidayat M, Baihaqi A. M., 2016, Sistem Pendukung Keputusan Untuk Pemilihan Hotel Dengan Simple Additive Weighting (SAW)

Berbasis Web, SNATI, ISSN:2302-3805

[2] Supriyono H., Sari C. P., 2015, Pemilihan Rumah Tinggal Menggunakan Metode Weighted Product, KHAZANAH INFORMATIKA, ISSN:2477-698X

[3] Ahmadi, A., \& Wiyanti, D. T., 2014, Implementasi Weighted Product (WP) dalam Penentuan Penerima Bantuan Langsung Masyarakat PNPM Mandiri Perdesaan, SNATI, 19-20.

[4] Kusumawardani, D., 2014, Sistem Pendukung Keputusan Penerima Bantuan Rumah Layak Huni Dengan Menggunakan Metode Weighted Product (WP), FASILKOM UDINUS.

[5] Kusrini, M.Kom. (2007). Kosep dan Aplikasi Pendukung Keputusan. Yogyakarta : Andi Publisher.

[6] Kusumadewi, S., Hartati, S., Harjoko, A., dan Wardoyo, R. (2006). Fuzzy Multi-Atribute Decision Making (FUZZY MADM). Yogyakarta: Penerbit Graha Ilmu.

[7] Kusumadewi, S. (2010). Aplikasi Logika Fuzzy untuk Pendukung Keputusan. Yogyakarta : Graha Ilmu. 